\title{
Pyosalpinx due to Cronobacter sakazakii in an elderly woman
}

\author{
Satoshi Ohira* (10, Eri Ikeda, Kyosuke Kamijo, Tomokuni Nagai, Koji Tsunemi, Natsuki Uchiyama, \\ Naoki Matsubara and Ryota Tachibana
}

\begin{abstract}
Background: Cronobacter sakazakii (C. sakazakii) is a bacterium known to cause severe neonatal infections in premature infants with the consumption of contaminated powdered milk formula. Adult infections are rare, and there have been no reports of pyosalpinx due to C. sakazakii to date.

Case presentation: We report a case of left pyosalpinx due to C. sakazakii in a sexually inactive postmenopausal woman. A 70-year-old woman presented to our hospital with left lower abdominal pain and fever. Abdominal computed tomography disclosed a cystic mass continuous with the left edge of the uterus. Urgent laparotomy revealed a ruptured left pyosalpinx with pus-like content. Left salpingo-oophorectomy, resection of the right tube, and washing of the abdominal cavity with saline were performed. Pathological examination of the left adnexa showed tubal tissue with acute inflammation and inflammatory exudate, which were compatible with pyosalpinx, and pus culture yielded C. sakazakii.
\end{abstract}

Conclusions: This is the first case report of pyosalpinx due to C. sakazakii. Cronobacter sakazakii infections in adult women might occur in the elderly, whose immunity has weakened. Further accumulation of cases of C. sakazakii infection is needed to clarify the etiology and behavior of C. sakazakii in adults.

Keywords: Cronobacter sakazakii, Pyosalpinx, Adult, Elderly woman, Case report

\section{Background}

Cronobacter sakazakii (C. sakazakii) is a Gram-negative, rod-shaped bacterium known to cause severe neonatal meningitis and necrotizing enterocolitis in premature infants with the consumption of contaminated powdered milk formula [1, 2]. Adult infections are rare [1], and there have been no reports of pyosalpinx due to C. saka$z a k i i$ to date. We describe a peculiar case of left pyosalpinx due to C. sakazakii in a sexually inactive elderly woman.

*Correspondence: osatoshi@shinshu-u.ac.jp

Department of Obstetrics and Gynecology, lida Municipal Hospital, 438

Yawatamachi, lida 395-8502, Japan

\section{Case presentation}

A 70-year-old nulligravid Japanese woman presented to our hospital with a four-day history of left lower abdominal pain and fever up to $38.5{ }^{\circ} \mathrm{C}$. Three days previously, pyelonephritis had been suspected and an antibiotic was administered at a previous clinic, but her symptoms did not improve. Tracing back her history, she had been totally blind since 14 years old, and diagnosed with depression one year ago and received medication of $15 \mathrm{mg} /$ day of Mirtazapine and $50 \mathrm{mg} /$ day of Chlorpromazine hydrochloride. Her dietary habits were common, but the toothbrushing was insufficient. Therefore, several teeth had been already lost. Her husband had died and she had been sexually inactive for the last four years. Physical examination revealed evident lower abdominal tenderness and rebound tenderness. Her body temperature was $39.4{ }^{\circ} \mathrm{C}$ and consciousness was drowsy. 
On gynecological examination, uterine cervical os was tightly closed without vaginal discharge. The uterine body was atrophic. A laboratory test showed leukocytosis with C-reactive protein of $24.36 \mathrm{mg} / \mathrm{dL}$. Neisseria gonorrhoeae deoxyribonucleic acid (DNA) and Chlamydia trachomatis DNA in the urine were both negative. Urgent abdominal computed tomography (CT) disclosed a cystic mass of $64 \times 30 \mathrm{~mm}$ with an equally enhanced wall (Fig. 1a). Because the cystic mass was continuous with the left edge of the uterus, a left adnexal abscess was suspected (Fig. 1b). CT also revealed ascites in the pelvic cavity and a diffusely enhanced peritoneum. Diffuse generalized peritonitis caused by rupture of the left adnexal abscess was suspected, and thus surgical intervention was planned.

Laparotomy revealed a ruptured left pyosalpinx with pus-like content (Fig. 2). The ascites had a foul smell and white moss was diffusely attached to the surface of the colon. The left ovary, uterus, and right ovary were atrophic. The right tube was slightly reddish with spreading of inflammation. Left salpingo-oophorectomy, resection of the right tube, and washing of the abdominal cavity with saline were performed. Pathological examination of the left adnexa showed tubal tissue with acute inflammation and inflammatory exudate, which were compatible with a pyosalpinx, and pus culture yielded $C$. sakazakii. In susceptibility testing of antibiotics, although this isolated C. sakazakii was resistant to Ampicillin, it was susceptible to other antibiotics including Cefazolin, Cefmetazole, Gentamicin, Levofloxacin, Imipenem, and Meropenem.

Because $\mathrm{CO}_{2}$ narcosis developed in the patient, after the operation, respirator management was needed in an intensive care unit. Moreover, polymyxin B-immobilized fiber column direct hemoperfusion was performed for two days. Bacteria were not detected by blood culture performed before the operation, but antibiotics of

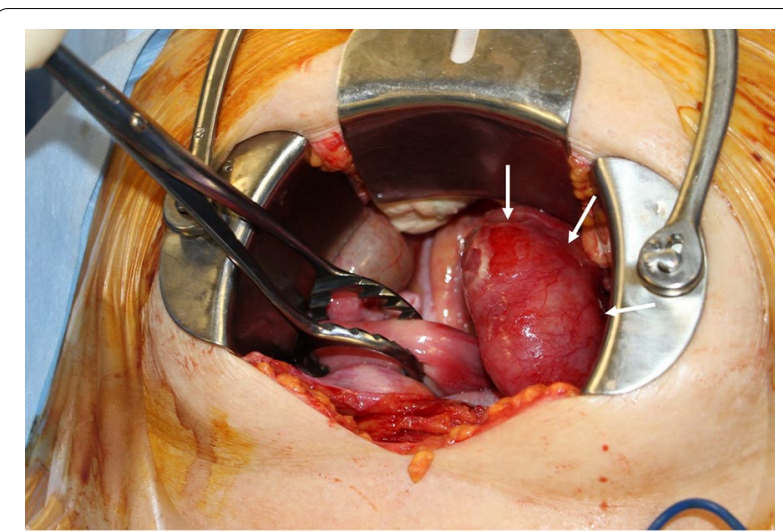

Fig. 2 Laparotomy reveals a ruptured left pyosalpinx with pus-like content (arrows)

Cefmetazole sodium for 3 days and Meropenem hydrate for 9 days were administered. The general state of the patient gradually improved and she was discharged from our hospital 21 days after the operation.

\section{Discussion and conclusions}

In 2007, organisms previously classified as Enterobacter sakazakii were reassigned to the new genus Cronobacter [2]. Cronobacter sakazakii has been isolated from clinical sources such as cerebrospinal fluid, blood and sputum, and food such as cheese, meat, and vegetables [2, 3]. Most reported cases of illness caused by C. sakazakii involve infants younger than 2 months old [4]. Premature infants with underlying medical conditions are at the greatest risk. Numerous outbreaks caused by C. sakazakii have been traced to contaminated powdered infant formula [2]. Meanwhile, 17 cases of illness in adults caused by $C$. sakazakii have been reported in detail [1, 5-13].

Only 7 case reports of C. sakazakii infections involving adult women have been published in the literature (Table 1) [1,5-8]. All of them and the current case were

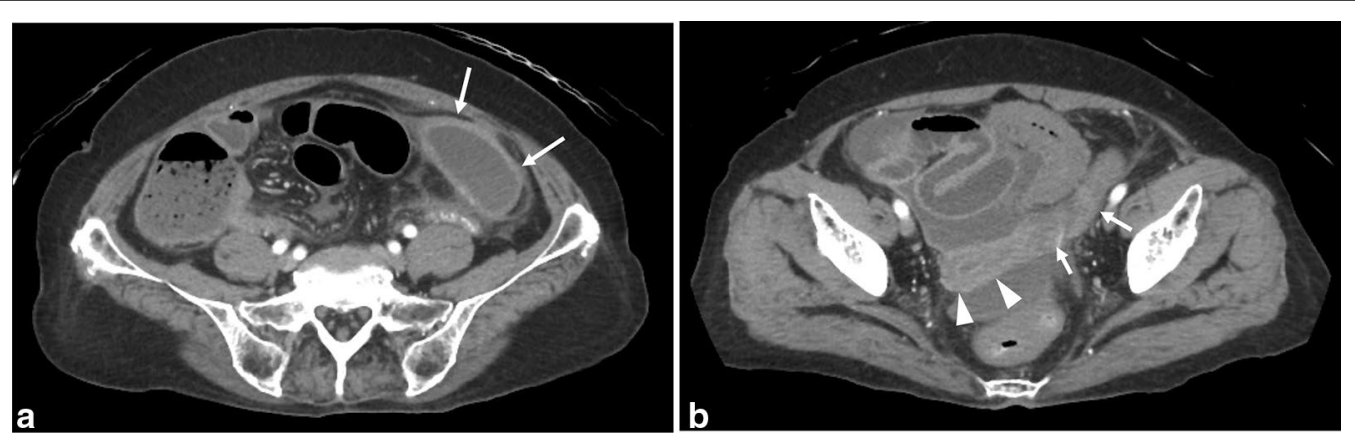

Fig. 1 Enhanced abdominal computed tomography demonstrates a cystic mass of $64 \times 30 \mathrm{~mm}$ with an equally enhanced wall in the left pelvic cavity (panel $\mathbf{a}$, arrows). The cystic mass is continuous with the left edge of the uterus (panel $\mathbf{b}$, Arrowheads show the uterus, and arrows show a cord structure connected to the mass) 
Table 1 Case reports of Cronobacter sakazakii infection in adult women

\begin{tabular}{|c|c|c|c|c|c|c|}
\hline References & Age & Isolation site & Clinical presentation & Underlying condition & Treatment (surgery and/or antibiotics) & Outcome \\
\hline Hawkins et al. [5] & 75 & Blood & Bacteremia & $\begin{array}{l}\text { Atrial fibrillation } \\
\text { Cerebral stroke }\end{array}$ & $\begin{array}{l}\text { Cefuroxime, Ceftriaxone } \\
\text { Ciprofloxacin }\end{array}$ & Recovered \\
\hline See et al. [1] & 75 & Blood & Splenic abscess & None & $\begin{array}{l}\text { Aspiration of abscess } \\
\text { Ceftriaxone, Metronidazole } \\
\text { Imipenem, Ciprofloxacin }\end{array}$ & Recovered \\
\hline Bhat et al. [6] & 63 & Urine & Urinary tract infection & Chronic renal failure & NA & Died \\
\hline \multirow[t]{3}{*}{ Lai [7] } & 73 & Bile, Blood & Biliary sepsis & Klatskin tumor & $\begin{array}{l}\text { Resection of common bile duct } \\
\text { Piperacillin-tazobactam } \\
\text { Gentamicin, Imipenem }\end{array}$ & Died \\
\hline & 82 & Blood & Abdominal aortic aneurysm & NA & $\begin{array}{l}\text { Aneurysmal repair } \\
\text { Ofloxacin, Piperacillin, Tazobactam }\end{array}$ & Died \\
\hline & 76 & Sputum & Pneumonia & Cecal volvulus & $\begin{array}{l}\text { Resection of cecum } \\
\text { Tobramycin, Ceftazidime, Ofloxacin }\end{array}$ & Died* $^{*}$ \\
\hline Tsai et al. [8] & 64 & Sputum & Pneumonia & Breast carcinoma & NA & Recovered \\
\hline Current case & 70 & Pus of pyosalpinx & Left pyosalpinx & Depression & $\begin{array}{l}\text { Salpingo-oophorectomy } \\
\text { Cefmetazole, Meropenem }\end{array}$ & Recovered \\
\hline
\end{tabular}

NA not available

* Pneumonia with isolation of Staphylococcus aureus and C. sakazakii. Cronobacter sakazakii might not be the causative agent of infection

of an advanced age ( $>60$ years), and 5 cases had underlying diseases such as malignant tumor, atrial fibrillation, cerebral stroke, cecal volvulus, and chronic renal failure. Therefore, it is suggested that $C$. sakazakii infections readily occur in women with weakened immunity. Isolation sites of C. sakazakii were blood, sputum, urine and bile. Most patients received surgery and/or the administration of antibiotics, but 4 died. In those cases of $C$. sakazakii infections who subsequently survived, cephem, quinolone or carbapenem antibiotic were administered $[1,5]$. The antibiotic therapy including cephem, quinolone and carbapenem might be necessary, but the administration of Ampicillin is not recommended. There have been no reports of pyosalpinx due to C. sakazakii to date; therefore, this is the first report of pyosalpinx.

Pyosalpinx and tubo-ovarian abscess are almost always complications of pelvic inflammatory disease and are sexually transmitted infections in many cases. Therefore, pyosalpinx and tubo-ovarian abscess are usually observed in young women; they are rarely found in older women. One hundred and ninety-four cases of pyosalpinx or tubo-ovarian abscess in postmenopausal woman have been reported in the literature [14-17]. Although typical organisms isolated in young women are Neisseria gonorrhea and Chlamydia trachomatis, those in reported postmenopausal women are Escherichia coli, Clostridium perfringens, Peptostreptcoccus, Group C Streptococcus, and Bacteroides fragilis [14, 15]. Among physiological mechanisms causing pyosalpinx or tubo-ovarian abscess, ascending infection from the lower genital tract is the most common reason, but ascending infection might be unlikely in sexually inactive postmenopausal women. Another hypothesis of bacterial spread by hematogenous seeding has been proposed as the origin of pyosalpinx in virgin patients [18], and this hypothesis might also be applicable to postmenopausal women. Although the cause of pyosalpinx in our patient remains unclear, we speculate that hematogenous infection by $C$. sakazakii occurred in the hydrosalpinx that existed, and pyosalpinx developed. One of the candidate original infection sites might be the oral cavity [9].

In summary, we describe the first reported case of pyosalpinx due to $C$. sakazakii in a postmenopausal elderly woman. Cronobacter sakazakii infections in adult women might be caused to the elderly women whom the immunity decreased. Further accumulation of cases of C. sakazakii infection is needed to clarify the etiology and behavior of C. sakazakii in adults.

\section{Abbreviations \\ C. Sakazakii: Cronobacter sakazakii; CT: Computed tomography; DNA: Deoxyri-} bonucleic acid.

\section{Acknowledgements}

Not applicable.

\section{Authors' contributions}

$\mathrm{SO}, \mathrm{El}, \mathrm{KK}, \mathrm{TN}, \mathrm{NU}$, and RT were in charge of this patient. KT, and NM helped to draft the manuscript. All authors read and approved the final manuscript.

\section{Funding}

Not applicable.

Availability of data and materials

All data presented in this report are included in this article. 


\section{Declarations}

Ethics approval and consent to participate

The study was sent to the ethical committee of lida Municipal Hospital and need for approval was waived.

\section{Consent to publish}

Written informed consent was obtained from the patient for publication of this case report. A copy of the written consent is available for review by the Editor-in-Chief of this journal.

\section{Competing interests}

The authors declare that they have no competing interests.

Received: 1 July 2020 Accepted: 25 March 2021

Published online: 01 April 2021

\section{References}

1. See KC, Than HA, Tang T. Enterobacter sakazakii bacteraemia with multiple splenic abscess in a 75-year-old woman: a case report. Age Ageing. 2007;36:595-6.

2. Lepuschitz S, Ruppitsch W, Pekard-Amenitsch S, Forsythe SJ, Cormican M, Mach RL, Piérard D, Allerberger F, EUCRONI Study Group. Multicenter study of Cronobacter sakazakii infections in humans, Europe, 2017. Emerg Infect Dis. 2019;25:515-22.

3. Kandhai MC, Reij MW, Gorris LG, Guillaume-Gentil O, van Schothorst M. Occurrence of Enterobacter sakazakii in food production environments and households. Lancet. 2004;363:39-40.

4. Iversen C, Forsythe S. Risk profile of Enterobacter sakazakii, an emergent pathogen associated with infant milk formula. Trends Food Sci Technol. 2003:14:443-54.

5. Hawkins RE, Lissner CR, Sanford JP. Enterobacter sakazakii bacteremia in an adult. South Med J. 1991:84:793-5.

6. Bhat GK, Anandhi RS, Dhanya VC, Shenoy SM. Urinary tract infection due to Enterobacter sakazakii. Indian J Pathol Microbiol. 2009·52:430-1.

7. Lai KK. Enterobacter sakazakii infections among neonates, infants, children, and adults. Medicine. 2001;80:113-22.
8. Tsai HY, Liao CH, Huang YT, Lee PI, Hsueh PT. Cronobacter infections not from infant formula. Taiwai Emerg Infect Dis. 2013;19:167-9.

9. Gosney MA, Martin MV, Wright AE, Gallagher M. Enterobacter sakazakii in the mouths of stroke patients and its association with aspiration pneumonia. Eur J Intern Med. 2006;17:185-8.

10. Emery CL, Weymouth LA. Detection and clinical significance of extended spectrum beta-lactamases in a tertiary-care medical center. J Clin Microbiol. 1997;35:2061-7.

11. Jimenez EB, Gimenez CR. Septic shock due to Enterobacter sakazakii. Clin Microbiol Newsl. 1982;4:30

12. Pribyl C, Salzer R, Beskin J, Haddad RJ, Pollock B, Beville R, Holmes B, Mogabgab WJ. Aztreonam in the treatment of serious orthopedic infections. Am J Med. 1985;78:51-6.

13. Tamigniau A, Vanhaecke V, Saegeman V. Cronobacter sakazakii bacteremia in a heart transplant patient with polycystic kidney disease. Transpl Infect Dis. 2015;17:921-5.

14. Chen KY, Tseng JY, Yang CY. Tubo-ovarian abscess with sepsis in a nonagenarian woman: a case report and literature review. BMC Womens Health. 2019;19:81.

15. Horenblas S, Bilski R. A case of a postmenopausal ruptured pyosalpinx: a rare finding at laparotomy for an acute abdomen. Eur J Obstet Gynecol Reprod Biol. 1984;17:351-4.

16. Tsianos GI, Papatheodorou SI, Michos GM, Koliopoulos G, Stefos T. Pyosalpinx as a sequela of labial fusion in a post-menopausal woman: a case report. J Med Case Rep. 2011:5:546.

17. Hida M, Anno T, Kawasaki F, Kaneto H, Kaku K, Okimoto N. A rare case of large pyosalpinx in an elderly patient with well-controlled type 2 diabetes mellitus: a case report. J Med Case Rep. 2018;12:286.

18. Humi Y, Bonollo M, Ferrero L, Taraschi G, Canonica C, Venturelli Reyes Lozano S. Pyosalpinx complicating chronic hydrosalpinx in a 50-year old virgo woman: a case report. BMC Womens Health. 2018;18:90.

\section{Publisher's Note}

Springer Nature remains neutral with regard to jurisdictional claims in published maps and institutional affiliations.

Ready to submit your research? Choose BMC and benefit from

- fast, convenient online submission

- thorough peer review by experienced researchers in your field

- rapid publication on acceptance

- support for research data, including large and complex data types

- gold Open Access which fosters wider collaboration and increased citations

- maximum visibility for your research: over 100M website views per year

At BMC, research is always in progress.

Learn more biomedcentral.com/submissions 